\title{
Planning the use of helicopters for supply distribution in response operations to sudden disasters
}

\author{
Planejando o uso de helicópteros para distribuição de suprimentos \\ em operações de resposta a desastres súbitos
}

Iran Rosa Xavier ${ }^{1}$ (D), Renata Albergaria de Mello Bandeira ${ }^{1}$ (D), Leandro de Oliveira Silva ${ }^{1,2}$ (D), Adriano de Paula Fontainhas Bandeira ${ }^{1}$ (D), Vânia Barcellos Gouvêa Campos ${ }^{1}$ [D

${ }^{1}$ Instituto Militar de Engenharia - IME, Seção de Fortificação e Construção - SE/2, Programa de Pós-graduação em Engenharia de Transportes, Rio de Janeiro, RJ. Brasil. E-mail: leandro.oliveira.sil@gmail.com

2Universidade de Uberaba, Departamento de Engenharia de Produção, Uberaba, MG, Brasil.

How to cite: Xavier, I. R., Bandeira, R. A. M., Silva, L. O., Bandeira, A. P. F., \& Campos, V. B. G. Planning the use of helicopters for supply distribution in response operations to sudden disasters. Gestão \& Produção, 28(1), e5000. https://doi.org/10.1590/1806-9649.2020v28e5000

\begin{abstract}
In disasters, when affected areas are remote or difficult to access, or when other ways of transport are not available, helicopters become the most appropriate vehicles to reach the victims, specialy in cases of floods, landslides and earthquakes. However, the planning of air transport operations in the context of a disaster response is of great complexity, so that operational research has significant application and potential contribution to the area. In this context, we propose a procedure that aims to optimize the use of helicopters in response operations to small and medium-scale disasters. The proposed procedure seeks to minimize the total time of operation and the mobilization of air resources during the last mile delivery in relief operations. The proposed procedure is applied on a post-disaster scenario, taking as basis the real characteristics of the response operation to the floods, occurred in 2011, in the mountain region of the state of Rio de Janeiro, Brazil. This paper highlights a methodological protocol for review and stratification of the journals for study and a proposal of this work with viable processes to aid decision-making in the process of distribution of the humanitarian supply chain using helicopters.
\end{abstract}

Keywords: Disaster; Transportation planning; Helicopters.

Resumo: Quando as áreas afetadas por um desatre são remotas ou de difícil acesso, ou quando outros meios de transporte não estão disponíveis, os helicópteros tornam-se os veículos mais adequados para chegar às vítimas, principalmente em casos de enchentes, deslizamentos de terra e terremotos. No entanto, o planejamento de operações de transporte aéreo no contexto de uma resposta a desastres é de grande complexidade, de modo que a pesquisa operacional tem aplicação significativa e potencial contribuição para a área. Nesse contexto, o presente artigo propõe um procedimento que otimiza o uso de helicópteros em operações de resposta a desastres de pequena e larga escala. O procedimento proposto minimiza o tempo total de operação e a mobilização de recursos

Recebido em Aug. 07, 2018 - Aceito em May 24, 2019

Suporte Financeiro: Project: CAPES Pro-Alerts 88887.091739 / 2014-01 - Decision support models for humanitarian logistics in preparation and response to natural disasters. General Coordinator: Silvio Hamacker. Associate: Renata Albergaria de Mello Bandeira. Financier (s): Coordination for the Improvement of Higher Education Personnel - Financial assistance. 
aéreos durante a entrega da última milha em operações de socorro. O procedimento é aplicado em um cenário pós-desastre, tomando como base as características reais da operação de resposta às enchentes, ocorridas em 2011, na região serrana do estado do Rio de Janeiro, Brasil. Este artigo destaca um protocolo metodológico para revisão e estratificação dos periódicos para estudo e uma proposta deste trabalho com processos viáveis para auxiliar a tomada de decisão no processo de distribuição da cadeia de suprimentos humanitária por meio de helicópteros.

Palavras-chave: Desastre; Planejamento de transporte; Helicópteros.

\section{Introduction}

One of the biggest logistical challenges in a response operation to disasters is the transport of aid resources (Kapucu, 2011). However, in situations of sudden disasters, transport infrastructure is often damaged or destroyed, so land routes are nonexistent, limited, congested, damaged or blocked. Therefore, when affected areas are remote or difficult to reach or when other modes of transport have failed, helicopters become the most suitable vehicles to reach beneficiaries in the first days after the event, as the time factor is critical at this stage of the event disaster management (Ozdamar, 2011; Xavier et al., 2015; Comaer, 2013; Brasil, 2014a).

However, unlike standard commercial supply chains, where there is usually a tradeoff between financial cost and time, for the context of humanitarian and emergency logistics operations, speed in victim care is the crucial factor in the chain. (Kovács and Spens, 2007; Oloruntoba and Gray, 2006). Thus, air transport operations depend on well-structured planning (Lopes, 1987; Mazzotti, 1987). Within this complex scenario, it is essential to elaborate a procedure that assists the decision-making regarding the planning of helicopter employment for logistic air transport activities in response to sudden disasters.

In Brazil, disaster response operations are coordinated by each state interdependently through the National System of Civil Protection and Defense (SINPDEC) of the National Secretariat of Civil Protection and Defense (SEDEC) of the Ministry of Regional Development. According to SINPDEC, each State Secretariat of Civil Protection and Defense is responsible for coordinating the planning, articulation and execution of civil protection and defense actions and providing the necessary resources and equipment for the response, as well as defining the proper procedures for use of helicopters for logistical air transport activities in the event of a disaster.

Therefore, this paper proposes a mathematical model of minimizing total mission time and deploying helicopters and people to improve distribution over the last mile of the humanitarian supply chain. Thus, at first, a literature review is conducted on cases of helicopter use in disaster response actions, in order to identify the main forms of application and restrictions to which they are subjected. Thus, the proposed model seeks to address the identified issues and is still adapted to the reality found in the country, as it treats the problem as that of scripting and considers of the characteristics of the assets employed in the country in this type of operation.

The proposed procedure is applied based on the characteristics of the post-disaster scenario of the Highland Region in the State of Rio de Janeiro, after the 2011 floods. Data for this application were collected based on reports and interviews with members 
of the Brazilian Air Force (FAB) and the Rio de Janeiro State Military Fire Brigade (CBMERJ) that acted in the scenario considered. Hence, while presenting the key features and capabilities of the helicopters most commonly used by federal agencies, $\mathrm{O} \mathrm{BESI}$ of Public Security and the armed forces, this study contributes to the SINPEDEC by presenting the guidelines for tactical and operational planning response operations to critical situation events. The importance in the study of the preparation, joint training and benefits of prior agreements between the various agencies is emphasized.

From this introduction, this paper is divided into four sections. Section 2 discusses, in the literature review, supply distribution problems in response operations to disasters with the use of helicopters occurring in seven disasters of similar magnitude. Section 3 presents the proposed procedure, whereas Section 4 presents the results based on the characteristics of the scenario considered. Finally, in section 5 are the conclusions, limitations and suggestions for improvement of this work.

\section{Review of helicopter use in sudden disasters}

After a disaster has occurred, one of the first possibilities for employing helicopters lies in aerial reconnaissance of the affected area, which considerably contributes to situational awareness of the extent and severity of the disaster. Thus, for such importance, this section presents a review of the use of helicopters in response actions to sudden disasters in order to understand the main forms of application and restrictions to which they are subjected. The objective of this stage of the research is to understand the main approaches taken to carry out the logistic air transportation of people and material in humanitarian aid operations, assessing the circumstances in which they occurred and the main restrictions to which they are subjected.

The review assesses Indian Ocean disaster response operations in 2004, USA in 2005, Pakistan in 2005, Brazil in 2008 and 2011, Haiti in 2010 and Japan in 2011. These seven disasters were selected for review due to the size of the impacts and mobilization of resources, available data, similarity of operating conditions and number of aircraft employed to alleviate people's suffering. Costa et al. (2015) also analyzed the logistics of Indian Ocean disaster response operations in 2004, Pakistan in 2005, Haiti in 2010, Brazil in 2011, and Japan in 2011, which reinforces the importance of these events and corroborates the choice to adopt them as a unit of analysis. However, it is important to emphasize that this article focuses on the use of helicopters, which was little analyzed in Costa et al. (2015).

Profiles of each of the events analyzed are detailed in Table 1, referencing the location and date of the occurrence of the disaster subgroup according to the classification of Em-Dat (2015), affected population, number of dead length and the number of helicopters employed. 
Table 1. Organization of the characteristics of the disasters selected for the literature review.

\begin{tabular}{|c|c|c|c|c|c|}
\hline $\begin{array}{l}\text { Place } \\
\text { (Date) }\end{array}$ & $\begin{array}{l}\text { Disaster } \\
\text { Subgroup } \\
\text { (EM-DAT) }\end{array}$ & $\begin{array}{c}\text { Affected } \\
\text { population }\end{array}$ & Dead & Extension & $\begin{array}{l}\text { Number } \\
\text { of Heli } \\
\text { Copters }\end{array}$ \\
\hline $\begin{array}{c}\text { Indian } \\
\text { Ocean } \\
(12 / 26 / 2004)\end{array}$ & $\begin{array}{l}\text { Earthquake } \\
\text { and Tsunamis }\end{array}$ & $23,788,866$ & 295,000 & $\begin{array}{l}\text { Cities and coastal areas of } \\
\text { Indonesia, Sri Lanka, India, } \\
\text { Malaysia and } 10 \text { other countries } \\
\text { in the region }\end{array}$ & $>185$ \\
\hline $\begin{array}{c}\text { USA } \\
(08 / 29 / 2005)\end{array}$ & $\begin{array}{l}\text { Hurricane } \\
\text { Katrina } 4\end{array}$ & 500,000 & 1,833 & $\begin{array}{l}\text { Mississippi and Louisiana } \\
\text { States }\end{array}$ & $>293$ \\
\hline $\begin{array}{c}\text { Pakistan } \\
(11 / 26 / 2008) \\
\end{array}$ & Earthquake & $5,128,309$ & 73,338 & $\begin{array}{l}\text { Northern Pakistan, Indian } \\
\text { Kashmir and Frontier Province }\end{array}$ & $>129$ \\
\hline $\begin{array}{c}\text { Brazil } \\
(11 / 26 / 2008)\end{array}$ & $\begin{array}{l}\text { Floods and } \\
\text { landslide }\end{array}$ & $1,500,015$ & 151 & $\begin{array}{l}\text { Municipalities of Itajaí, Ilhota, } \\
\text { Gaspari, Luiz Alves and } 5 \text { other } \\
\text { municipalities of the region }\end{array}$ & $>25$ \\
\hline $\begin{array}{c}\text { Haiti } \\
(01 / 12 / 2010)\end{array}$ & Earthquake & $3,700,000$ & 222,570 & $\begin{array}{l}\text { Port au Prince, Leogan and } \\
\text { Jacmel urban centers }\end{array}$ & $>150$ \\
\hline $\begin{array}{c}\text { Brazil } \\
(01 / 10 / 2011)\end{array}$ & $\begin{array}{l}\text { Floods and } \\
\text { landslide }\end{array}$ & 45,000 & 900 & $\begin{array}{l}\text { Mountainous Region of the } \\
\text { State of Rio de Janeiro }\end{array}$ & $>30$ \\
\hline $\begin{array}{l}\text { Japan } \\
(03 / 11 / 2011)\end{array}$ & Earthquake & 368,820 & 19,846 & $\begin{array}{l}\text { Miyagi, Iwate, Ibaraki and } \\
\text { Fukushima Municipalities }\end{array}$ & $>209$ \\
\hline
\end{tabular}

Source: Costa et al. (2015).

In all the disasters listed in Table 1, the main entry points for humanitarian aid were airports and ports near the affected areas with infrastructure available to carry out the operation. Due to their magnitude and extent, all disasters have deployed multi-depot transportation networks (primary and secondary) with four primary functions: maintenance, consolidation, fractionation and product blending. In the case of Hurricane Katrina in the US and the Indian Ocean tsunami, some aircraft carriers functioned as supply distribution hubs. In Brazil, existing facilities have been adapted to function provisionally as warehouses and air bases (Costa et al., 2015; Xavier et al., 2015).

Helicopter use in air reconnaissance activities in the affected region is observed in the US in 2005 and Pakistan in 2005. Reconnaissance information assisted in defining potential demand points, assessing transport infrastructure conditions, and other planning steps of the operation. However, depending on the nature of the disaster, air reconnaissance may not be immediately applicable, as was the case in Brazil in 2008, when weather conditions delayed the release of flights (Costa et al., 2015; Xavier et al., 2015).

Logistic air transport missions to move material and personnel are responsible for alleviating the suffering of many victims, especially in the distribution of the last mile (Balcik et al., 2008). Observing the first days after the disaster strikes, helicopters ensure the immediate survival of victims by carrying out "search and rescue", "aeromedical evacuations " and "logistics air transport" missions (Balcik et al., 2008). To perform the search and rescue missions and aeromedical evacuations, aircraft configured with specific equipment and specialized crew are required. Through the analysis of the response actions to disasters presented in Table 1, helicopters were employed to transport Class I (subsistence materials), Class II (stewardship materials) and Class VIII (medical supplies) supplies.

Response periods with helicopters vary according to event characteristics, need for immediate service, transport infrastructure conditions, aircraft availability, the possibility of using another model and other factors (Xavier et al., 2015). The approximate duration of air operations for the disasters described in Table 1 was 11 weeks for the Indian Ocean tsunami in 2004; 04 weeks for Hurricane Katrina in the USA in 2005; 15 
weeks for the earthquake in Pakistan in 2005; 02 weeks for the landslide in the hill of Baú in 2008; 14 weeks for Haiti earthquake in 2010; 02 weeks for the landslide in Rio de Janeiro in 2011; 15 weeks for the 2011 earthquake and tsunami in Japan. The large amount of flight hours in the Indian Ocean, USA, Pakistan and Brazil in 2011 meant the physical and psychological fatigue of the crew and the technical maintenance of the aircraft, resulting in periods of temporary unavailability of air assets (Costa et al., 2015; Xavier et al., 2015).

Helicopters with medium and heavy transport capacity are the main assets provided by foreign nations to assist in humanitarian missions (Xavier et al., 2015). For instance, in 2008 and 2011 in Brazil, light transport aircraft belonging to the Brazilian state and civil aviation security aircraft and medium transport aircraft from the military and armed forces were used.

In all cases, the answers involved intergovernmental actions (state federal and local) operations and inter - sector, through a complex network of actors composed of public bodies, private enterprises and non-profit organizations (Xavier et al., 2015). In this scenario, the need to deploy an Air Operations Center (COA) was observed and deployed. The proposal was to unify and manage the various missions and aircraft to avoid duplication of tasks and increase the safety of air space, as recommended in the manuals of the Departament of Defense Support to Foreign Disaster Relief (DOD) and the Office for Coordination of Humanitarian Affairs (OCHA) (Brasil, 2013).

The analysis of helicopter response actions, described by Clementson And Fisher (2011) and Myers (1998), allows us to identify operational constraints that can be incorporated into mathematical modeling to minimize operation time and maximize service operations performance: conditions climate (defining time windows); aircraft availability; vehicle capacity (weight, volume, passengers); maximum crew workday (fatigue control); maximum daily workday of aircraft; number of trips allowed; on-ground logistics support (maintenance, fuel, supplies); budgetary limit of the operation (Xavier et al., 2015)

The evaluation of the main aspects of the logistic air transport of the studied events made it possible to identify common conditions that will be considered for the procedure to aid decision making and to improve logistic performance in humanitarian disaster response.

Section 3 presents the proposed procedure for helicopter operations in order to optimize the use of air and meet the demand for supplies and people in the shortest possible time based on the characteristics raised in this review.

\section{Proposed procedure for planning the helicopter transport and deployment system}

The proposed procedure for planning the use of helicopters in logistic air transport in response operations follows a five-step structure: situational assessment, assessment of transport needs, selection and mobilization of air assets, deployment of logistics air transport and route estimation of the missions.

In step 1, data on the post-disaster situation are collected and the response capacity required to better understand the impacts, human and material damage in the affected region. Preliminary assessment should be carried out within 24 hours (Icrc, 2008) and thereafter further assessment should be done within 48 to 72 hours after the disaster. At this stage, the relevance of the analysis of the transport infrastructure conditions is highlighted, which indicates the difficulties in the provision of humanitarian aid and may suggest the use of air resources.

In step 2, there is a survey of transport needs based on the estimated demand of the beneficiaries. The work of Icrc (2008) and Paho (2008) provide guidance for assessing 
the needs of people affected in emergency situations. According to Benini et al. (2009), Comaer (2011) and Xavier (2016), the main aid items carried by helicopters in response operations are: water, food, medicines, clothing, support equipment and fuels. In addition, the main transported teams are those that perform impact assessment, search and rescue, made up of medical teams, firefighters and reporters.

In stage 3, the conditions of employability of the air assets are evaluated, based on the knowledge of vehicle capacities, limitations and availability (Brasil, 2013; U.S. Army, 2014; USAF, 2011). Clementson \& Fisher (2011) point out that the main information used in planning the helicopters are the maximum take-off weight (Max Cargo Weight - MCW) and the maximum passenger capacity (Max Passenger Capacity - MPC).

In step 4, the necessary requirements for the implementation of the helicopter logistic air transport system are considered, such as: definition of the operating base and landing zones; air operations center, which is responsible for receiving air transport requests and planning missions; and airspace control (Myers, 1998; COMAER, 2005; COMAER, 2013).

Step 5 is responsible for estimating mission itineraries for moving material and / or personnel and the number of aircraft required from the information obtained in the previous steps. This is a time-window routing problem, which is treated in this procedure as a straight graph $G=(V, A)$ where $|V|=n+2$ is the depot and is represented by vertices 0 and $n+1$. Viable vehicle routes must start at node 0 and end at node $n+1$, with the aim of minimizing the sum of the route times of each aircraft in the selected to meet the distributed demand at the various points in the affected area (Equation 1). Table 2 presents the set of indices and parameters used for the construction of the model that aims to minimize the total operation time. Furthermore, the mathematical model consists of eight subjective inequalities detailed in equations 2-9.

Table 2 Identification of index and parameter sets.

\begin{tabular}{|c|c|}
\hline $\begin{array}{c}\text { Indexes I } \\
\text { Parameters }\end{array}$ & Description \\
\hline $\mathrm{K}$ & available vehicles, where $\mathrm{k}=\{1,2, \mathrm{~m}\}$ \\
\hline V & set of nodes that make up the network, where $v=\{0,1,2, n+1\}$ \\
\hline THE & set of nodes that make up the arcs, where $A=\{(0,1),(1,1), \ldots,(i, j)\}$ \\
\hline no & representation of a node within the network \\
\hline $\mathrm{DEM}_{\mathrm{i}}$ & Required load demand in i, in [kg] \\
\hline $\mathrm{D}_{\mathrm{ij}}$ & linear distance between nodes i and j, in [km] \\
\hline VEL & operating speed set for the vehicle in $[\mathrm{km} / \mathrm{h}]$ \\
\hline CAP & vehicle carrying capacity in [kg] \\
\hline $\mathrm{T}_{\mathrm{ij}}$ & travel time between iej, in [hours] \\
\hline $\mathrm{x}_{\mathrm{ij}}$ & $\begin{array}{l}\text { decision variable; defined by } 1 \text { if vehicle } \mathrm{k} \text { traverses the section between nodes } \\
\mathrm{i} \text { and } \mathrm{j} \text {; or } 0 \text {, otherwise. }\end{array}$ \\
\hline $\mathrm{S}_{\mathrm{i}}$ & length of service in attendance at $i$, where $S_{0}=S_{n}+1=0$ \\
\hline$a_{i}$ & lower bound of demand point time window i, in [hours] \\
\hline$b_{i}$ & upper limit of time window of demand point $\mathrm{i}$ in [hours] \\
\hline $\mathrm{M}_{\mathrm{ij}}$ & constant required for linearization of the time window constraint \\
\hline T LRF & aircraft loading and / or refueling time in [min] \\
\hline TUL & aircraft unloading time in [min] \\
\hline MTV & upper limit flight time on a route in [hours] \\
\hline MJT & maximum daily workday allowed in [hours] \\
\hline $\mathrm{TM}_{\text {Routes }}$ & average route time (transfer time plus load, unload and service times), or cycle time \\
\hline TotalDEM & total demand to be met \\
\hline
\end{tabular}




\section{Purpose Function:}

$$
\min \sum_{k \in K} \sum_{i, j) \in A}^{j} T_{i j} x_{i j}
$$

\section{Subject to:}

a) limitation that each point of demand is visited only once;

$$
\sum_{k \in K} \sum_{j \in \delta+(i)} x_{i j}=1, \forall_{i} \in N
$$

b) base of operation receives one visit from each vehicle;

$\sum_{k \in K} \sum_{j \in \delta+(0)} x_{0 j k}=1, \forall_{k} \in N$

c) guarantee of conservation of flow in the nodes;

$\sum_{k \in K} \sum_{j \in \delta-(i)} x_{i j k}-\sum_{k \in K} \sum_{j \in \delta+(i)} x_{i j k}=0, \forall_{i} \in N$

d) guarantee of conservation of flow in the nodes;

$\sum_{j \in \delta-(n+1)} x_{i, n+1}^{k}=1, \forall_{k} \in K$

e) attendance within the time window;

$w_{j}^{k} \geq w_{i}^{k}+S_{i}+T_{i j}+M_{i j}\left(1-x_{i j}^{k}\right), \forall_{k} \in K,(i, j) \in \forall$

f) statement of the time window limit;

$w_{i}^{k} \geq a_{i}+\sum_{j \in \delta+(i)} \max \left\{0, a_{j}-a_{i}+S_{j}+T_{i j}\right\} x_{i j}^{k} \in\{0,1\}, \forall_{k} \in K, i \in V$

$w_{i}^{k} \geq b_{i}+\sum_{j \in \delta+(i)} \max \left\{0, b_{j}-b_{i}+S_{j}+T_{i j}\right\} x_{i j}^{k} \in\{0,1\}, \forall_{k} \in K, i \in V$

g) statement that $x_{i j}^{k}$ is a binary variable; 
$x_{i j}^{k} \in\{0,1\}, \forall_{i, j, k}$

To solve this problem, we developed an algorithm in software MatLab version 2015 of the Mathworks, based on the Clarke and Wright (1964) saving algorithm, with the implementation of local improvement method 2-opt and the proposed route guidance strategy by Gama (2011). Finally, the minimum number of vehicles needed to meet the demand at all service points without incurring a shortage should be determined using the concept of minimum theoretical number of vehicles (NumVeic ${ }_{\min }$ ) proposed by Battini et al. (2014), according to Equation 10.

$$
\text { NumVeic }_{\text {min }}=\frac{D E M_{\text {total }}}{\frac{M J T}{T M_{\text {routes }}} x C A P_{\text {veic }}}
$$

However, the minimum number of vehicles of the same type may not be available. Thus, it is considered that the decision maker will have three solution options: (i) perform only the priority demand points; (ii) request the complementation of the fleet with aircraft of the same type; or (iii) request the mobilization of aircraft with different characteristics. In this third case, considering a heterogeneous fleet, larger aircraft should be allocated preferentially, provided that the best utilization of their capabilities is guaranteed. Therefore, for the largest capacity aircraft available, itneraries which have the highest product value between occupancy rate and cycle shall be chosen.

\section{Application of the procedure based on the characteristics of the Brazilian disaster of the Rio de Janeiro Highlands in 2011}

This section presents the application of the proposed helicopter deployment procedure to the air transport system planning in response operations in a scenario similar to the reality after the disaster in the Rio de Janeiro State Highlands in 2011. The choice of this event is due to the fact that it is considered by the UN as the 8th largest landslide in the world in the last 100 years, besides being the response action that employed the largest number of helicopters. Still, the mountainous region of the State of Rio de Janeiro is highly vulnerable to sudden disasters, with continually monitored municipalities and major threats of damage caused by weather events.

The data and information for the development of this analysis was based on the final mission reports and interviews with officers of the Brazilian Air Force (FAB) and the Rio de Janeiro State Fire Department (CBMERJ). The interviews were conducted with 10 military personnel who participated in the event, four firefighters from CBMERJ and six FAB officers. Respondents have experience in disaster management and have worked in their respective bodies for at least eleven years.

\subsection{Step 1: Disaster Assessment}

In January 2011, the mountainous region of Rio de Janeiro suffered a strong hydrometeorological impact, characterized by a flood with abrupt overflow, causing several damages (Brasil, 2014b). The seven most affected municipalities were Areal, Bom Jardim, Nova Friburgo, Petrópolis, Sumidouro, São José do Vale do Rio Preto and 
Teresópolis, in an area of 3,611 $\mathrm{km}^{2}$. Also, 1,600 km of highways were damaged and $340 \mathrm{~km}$ being totally destroyed.

Through information obtained by aerial reconnaissance, FAB reports and CBMERJ and media reports, it was possible to identify 26 isolated points in the affected area that needed to receive humanitarian assistance, as shown in Figure 1.

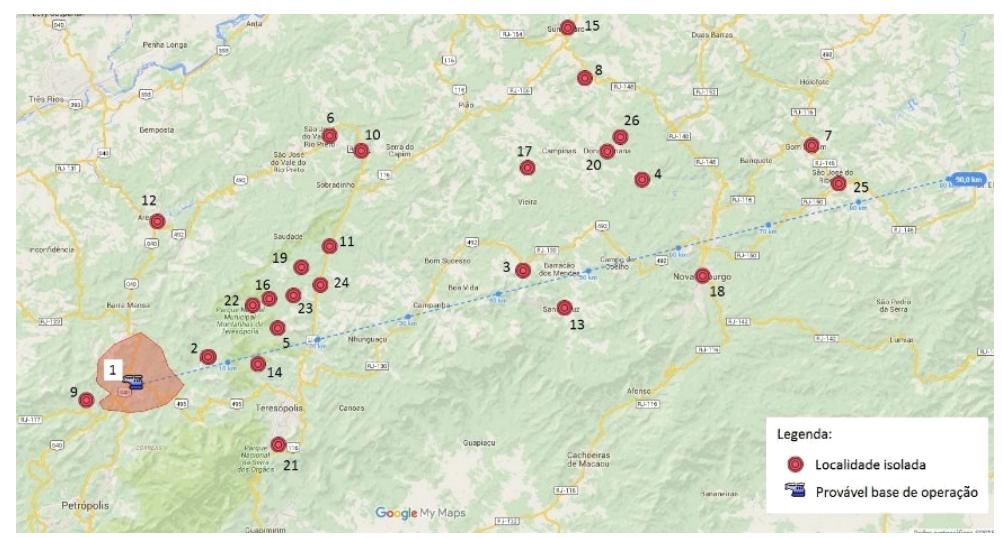

Figure 1. Service points in the municipalities.

\subsection{Step 2: Assessing logistical air transport needs}

In Brazil, obtaining the information of food transport needs is the responsibility of the Disaster Management Center, which define quantity, urgency and priority. It is noteworthy that this study is focused on the last mile of humanitarian supply chain and believes that the needs for service points, shown in Figure 1, have been estimated and identified.

The estimated demands for material transportation at each service point are presented in Table 3, and from the central depot (point P1) a total of $20.110 \mathrm{~kg}$ of material is distributed among the 25 locations (Table 3). Moreover, in this hypothetical scenario, we envision adressing the transport of rescue teams who will work in the local fi ned in Figure 1, amounting to a total demand of 231 profissionais distributed in 19 service points (Table 4). These estimated quantities were based on interviews with COMAER (2011).

Table 3. Demand for transporting supply resources in $\mathrm{kg}$.

\begin{tabular}{ccccccccccccc}
\hline \multicolumn{10}{c}{ Service Points } \\
\hline P1 & P2 & P3 & P4 & P5 & P6 & P7 & P8 & P9 & P10 & P11 & P12 & P13 \\
\hline 0 & 600 & 750 & 300 & 880 & 1600 & 2300 & 600 & 1500 & 300 & 900 & 1200 & 500 \\
\hline P14 & P15 & P16 & P17 & P18 & P19 & P20 & P21 & P22 & P23 & P24 & P25 & P26 \\
\hline 400 & 1600 & 830 & 630 & 1100 & 600 & 500 & 700 & 650 & 300 & 400 & 200 & 700 \\
\hline
\end{tabular}

Table 4. Demand for transportation of people.

\begin{tabular}{ccccccccccccc}
\hline \multicolumn{10}{c}{ Service Points } \\
\hline P1 & P2 & P3 & P4 & P5 & P6 & P7 & P8 & P9 & P10 & P11 & P12 & P13 \\
\hline 0 & 4 & 17 & 9 & 12 & 8 & 20 & 0 & 27 & 2 & 0 & 12 & 0 \\
\hline P14 & P15 & P16 & P17 & P18 & P19 & P20 & P21 & P22 & P23 & P24 & P25 & P26 \\
\hline 3 & 16 & 0 & 2 & 30 & 20 & 0 & 16 & 2 & 5 & 0 & 10 & 7 \\
\hline
\end{tabular}




\subsection{Step 3 - Checking Airway Availability}

Helicopter organizations operating in the region are consulted to register available aircraft for response. Due to the intensity of human and material damage in a large area, the Federal Government released the use of the Armed Forces in support of the Rio de Janeiro State Civil Defense operations.

Among the registered aircraft models, the AS350, Bell Huey H1, UH60, AS332 and EC725 models are identified as the best vehicles for disaster scenarios and all are considered in the study.

In summary, the AS350 model is a common aircraft in Brazil, with a transport capacity of 4.3 tons; The Bell Huey $\mathrm{H} 1$ is a military, multipurpose, midsize model designed for search and rescue missions and can carry up to 13 people and 4.3 tons of cargo; the UH60 model is used in extreme conditions missions and can carry up to 14 passengers; the AS332 has a high capacity and can carry 25 combatants or six injured on stretchers and 10 passengers, lifting 4.5 tons; the model EC725 is an aircraft applied to multiple long-range tactical transport missions, medical aero evacuation, logistical support, search and rescue and capable of carrying 3.8 tons and 29 passengers or installing up to 11 stretchers and seats for a four-person medical team.

\subsection{Step 4 - Implementation of Logistic Air Transport}

In this step, you should consult the registration database to identify the main airfields and helipads near the affected area, as well as the possible operation points registered in advance by the Civil Defense and experts in air operations. Also, whenever possible, the base of operations should be located in a safe area (cold zone), as close as possible to the affected place (hot zone). Thus, due to the execution of other disaster response activities, such as the Armed Forces Campaign Hospital, the FAB determined the installation of a deployment base in the area of the Itaipava Exhibition Park in the municipality of Petrópolis, from where airspace control is performed, as highlighted in Figure 1.

\subsection{Step 5 - Estimate of Itineraries for Missions and Quantity of Aircraft}

At this stage of the procedure, two transport situations are considered. The first is related to the supply of transport to the service points defined in Table 3, from the base of deployed operations in Itaipava/Petrópolis. The second considers the transport of persons for specified demand points defined in Table 5, and fire teams are also sent to the affected areas from the Itaipava Exhibition center / Petropolis.

To estimate the itineraries and the number of aircraft required to serve the affected population in isolation, the AS350, Bell Huey H1, UH-60, AS332 and EC725 aircraft selected in Step 3 were considered. Confidentiality required by the FAB, logistics costs of flight hours have presented just plain character and reflect an order of magnitude, having been obtained from Abreu works (Abreu, 2008) and Clementson \& Fisher (2011). The parameters for the AS350, Bell Huey H1, UH-60, AS332 and EC725 aircraft are presented in Table 5. 
Table 5. Available vehicle parameters.

\begin{tabular}{lccccc}
\hline \multicolumn{1}{c}{ Model } & $\begin{array}{c}\text { AS350 } \\
\text { (1) }\end{array}$ & $\begin{array}{c}\text { Bell Huey H1 } \\
\text { (2) }\end{array}$ & $\begin{array}{c}\text { UH-60 } \\
\text { (3) }\end{array}$ & $\begin{array}{c}\text { AS332 } \\
\text { (4) }\end{array}$ & $\begin{array}{c}\text { EC725 } \\
\text { (5) }\end{array}$ \\
\hline Number of vehicles available (un) & 8 & 2 & 2 & 3 & 2 \\
\hline Cruising Speed (km/h) & 235 & 205 & 280 & 260 & 260 \\
\hline Supply Load Capacity (kg) & 400 & 1200 & 1525 & 2000 & 2400 \\
\hline Charging / Refueling Time (min) & 15 & 20 & 30 & 30 & 30 \\
\hline Number of Passengers (un) & 3 & 10 & 12 & 22 & 28 \\
\hline Fuel consumption & 157 & 275 & 440 & 490 & 650 \\
\hline Logistic cost of flight time (US\$) & 884,21 & 2150 & 4700 & 7500 & 8600 \\
\hline
\end{tabular}

The time taken for helicopter landing and takeoff approaches was 2 minutes (Mazzotti, 1987). The loading/refueling and discharging times of medium-sized aircraft are considered to be 30 minutes (Clementson \& Fisher, 2011; Ozdamar, 2011). For the other aircraft, average reference values obtained through interviews with FAB officers were considered. It is emphasized that the loading time is considered proportional to the transported load.

It should be noted that for both situations, 1 (material transportation) and 2 (transportation of specialized teams), the following were considered: a central warehouse located at the base of operations (P1) (Table 3), the matrix of distances between the central warehouse to each service point, and the maximum working hours per vehicle equal to 720 minutes shifting the cruising speed, load capacity and charging time / discharging defined in Table 4.

\subsubsection{SITUATION 1 - TRANSPORT OF MATERIAL TO THE AFFECTED AREA}

In the transportation of material, the 26 service points totaling $20,110 \mathrm{~kg}$ and the maximum working time per vehicle equal to 720 minutes are considered. The application of the model generated the results presented in Table 6 .

Table 6. Estimates resulting from applying the procedure to the situation 1.

\begin{tabular}{lccccc}
\hline \multicolumn{1}{c}{ Model } & AS350 & Bell Huey & UH-60 & AS332 & EC725 \\
& $(\mathbf{1})$ & H1 (2) & (3) & (4) & (5) \\
\hline Total Mission Time (h) & 48.42 & 22.02 & 17.59 & 16.20 & 15.17 \\
\hline Loading / Unloading Time (h) & 25.14 & 11.17 & 11.17 & 10.06 & 9.14 \\
\hline Total flight hours (h) & 23.29 & 10.85 & 6.42 & 6.15 & 6.03 \\
\hline Total number of itineraries (un) & 54 & 19 & 13 & 11 & 11 \\
\hline Number of fully loaded itineraries (un) & 39 & 5 th & 1 & 1 & 1 \\
\hline Average stops per itinerary (pcs) & 3.07 & 3.53 & 4 & 4.36 & 4.36 \\
\hline Maximum stops per itinerary (pcs) & 4 & 5 & 5 & 5 & 6 \\
\hline Minimum cycle time (min) & 28.17 & 39.91 & 38.58 & 57.57 & 49.24 \\
\hline Average Cycle Time (min) & 53.80 & 69.55 & 81.19 & 88.37 & 82.76 \\
\hline Maximum cycle time (min) & 81.47 & 94.65 & 101.88 & 106.18 & 108.41 \\
\hline Minimum Route Occupancy Rate & $50 \%$ & $54.17 \%$ & $38.89 \%$ & $75 \%$ & $54.55 \%$ \\
\hline Average Route Occupancy Rate & $93.1 \%$ & $88.2 \%$ & $85.94 \%$ & $91.4 \%$ & $83.09 \%$ \\
\hline Maximum occupancy rate of itineraries & $100 \%$ & $100 \%$ & $100 \%$ & $100 \%$ & $100 \%$ \\
\hline Theoretical minimum number of aircraft (un.) & 4 & 2 & 2 & 2 & 2 \\
\hline Total fuel consumption (kg) & 3656 & 2984 & 2824 & 3012 & 3920 \\
\hline Mission Budget Total (US \$) & 20590 & 23329 & 30164 & 46098 & 51865 \\
\hline
\end{tabular}


The Figure 2a presents an analysis as to total task time, which considers air travel times and time on the ground (loading/supply) and it is observed in this figure that all four medium sized aircraft models have lower values of half the total time of smaller aircraft. Although the time for loading of each AS350 aircraft is lower than the other aircraft, its total loading time (25.14 hours) was higher than the other models. This is due to the larger number of aircraft required to perform the same total demand operation, corroborated by the relationship between loading time and load capacity of each vehicle.

In assessing the number of planned itineraries for the five models, it is observed that the load capacity has direct influence on the number of scripts, as shown in Table 6. In addition, it was possible to infer that the direct care percentage (depositpoint-deposit) in relation to the total number of trips is better for the AS350 model, as most calls from this model are straightforward.

Figure 2 (b) displays the maximum, average and minimum cycle times for aircraft models. The maximum time of cycles for all models range from $1 \mathrm{~h} 20 \mathrm{~min}$ to $1 \mathrm{~h} 46 \mathrm{~min}$ and the minimum time cycles from 28 min to 57 mins. Still, in Figure 2 (c), by evaluating the maximum, minimum and average occupancy rates of each type of vehicle, it is possible to identify that models of vehicles, when in direct service times, use all their load capacity. In addition, when evaluating average occupancy rates, values above $80 \%$ can be verified which demonstrates that optimization applied enabled a good use of vehicles' load capacity.

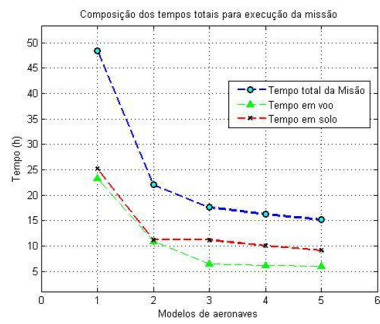

(a)

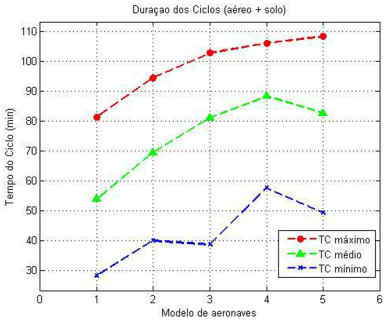

(b)

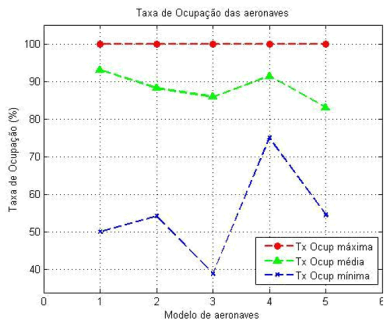

(c)

Figure 2. Composition of execution times of the mission vehicle models $x(a) d$ - time the cycle $\mathrm{s} \vee$ ersus vehicle types (b) and occupancy rates $\mathrm{x}$ vehicle models.

Since the optimization has met all constraints, the decision maker can estimate the theoretical minimum number of aircraft using Equation 10. In this case, four AS350 aircrafts or two identical aircraft of any of the other models are required. The number of itineraries is minimized by the number of aircraft when considering time as a major factor. To illustrate the optimal aircraft routing solution, the AS350 and EC 725 models are chosen and shown in Figure $3 a$ and $b$.

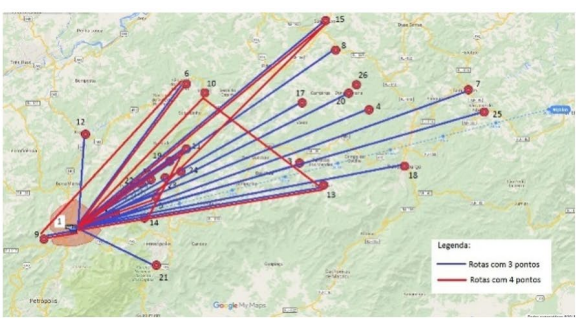

(a)

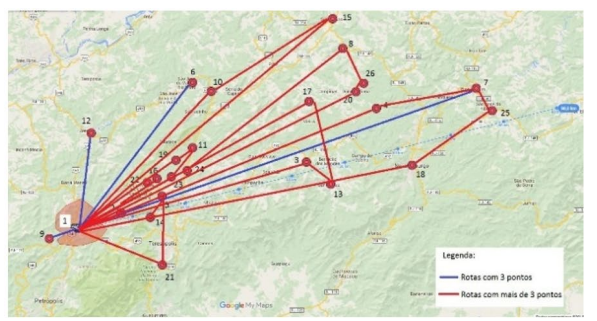

(b)

Figure 3. Routes obtained using the aircraft AS 350 (a) and routes obtained using the aircraft EC 725 (b) 
In Figure 3a, it is possible to identify the predominance of itineraries with 3 points of direct attendance, since this aircraft has lower load capacity. On the other hand, in Figure $3 \mathrm{~b}$ the itineraries composed by more than 3 points of attendance predominate.

\subsubsection{SITUATION 2 - TRANSPORT OF SPECIALIZED PERSONS FOR RESPONSE ACTIONS}

In this second situation, the demands for personnel transportation refer to the 19 service points identified in Table 5, totaling 231 people, a warehouse located in the base of operations (P1), the distance matrix, the maximum workday per vehicle equal to 720 minutes and vehicles using cruising speed, with passenger capacity and boarding / disembarking times. The results obtained by applying the solution strategy of Step 5 are presented in Table 7.

Table 7. Estimates resulting from applying the procedure to the situation 2 .

\begin{tabular}{lccccc}
\hline \multicolumn{1}{c}{ Model } & AS350 & $\begin{array}{c}\text { Bell Huey } \\
\text { H1 }\end{array}$ & UH-60 & AS332 & EC725 \\
\hline Total Mission Time (h) & 39.92 & 17.87 & 13.54 & 9.92 & 8.17 \\
\hline Loading / Unloading Time (h) & 7.4 & 5.92 & 4.93 & 4.04 & 3.17 \\
\hline Total flight hours (h) & 32.52 & 11.95 & 8.61 & 5.89 & 5 \\
\hline Total number of itineraries (un) & 76 & 23 & 20 & 11 & 9 \\
\hline Number of fully loaded itineraries (un) & 67 & 15 & 11 & 2 & 1 \\
\hline Average stops per itinerary (un) & 3.05 & 3.3 & 3.4 & 3.91 & 4.22 \\
\hline Maximum stops per itinerary (un) & 5 & 5 & 5 & 6 & 7 \\
\hline Minimum cycle time (min) & 15.06 & 24.99 & 17.67 & 29.41 & 26.8 \\
\hline Average Cycle Time (min) & 31.51 & 46.62 & 40.62 & 54.12 & 54.47 \\
\hline Maximum cycle time (min) & 59.35 & 68.05 & 63.25 & 75.86 & 86 \\
\hline Minimum Route Occupancy Rate & $66.67 \%$ & $70 \%$ & $33.33 \%$ & $54.55 \%$ & $42.86 \%$ \\
\hline Average Route Occupancy Rate & $97.3 \%$ & $96.52 \%$ & $93.5 \%$ & $91.74 \%$ & $88.1 \%$ \\
\hline Maximum occupancy rate of itineraries & $100 \%$ & $100 \%$ & $100 \%$ & $100 \%$ & $100 \%$ \\
\hline Theoretical minimum number of aircraft & 4 & 2 & 2 & 1 & 1 \\
(un) & & & & & \\
\hline Total fuel consumption (kg) & 5105 & 3286 & 3786 & 2884 & 3249 \\
\hline Mission Budget Total (US \$) & 28752 & 25692 & 40443 & 44143 & 42995 \\
\hline
\end{tabular}

As for the total mission time (air travel times and time on the ground), it is observed that all models Bell Huey H1, UH-60, AS332 and EC725 hold values that are lower than half the total time of AS350 model, as shown Figure 4a and Table 7. Although the shipping time of the AS350 model was shorter than the other models, its total charging time ( 7.40 hours) was longer. This is due to the larger amount of aircraft the AS350 needs to fulfill mission planning.

When assessing the number of routes provided for all five models (Figure $4 b$ ), it is observed that the passenger capacity has direct influence over the amount of routes. The results presented in Table 7 highlight that, on average, models work with direct service (depot-depot) to three itinerary points out of a maximum of five itinerary points. The maximum, average and minimum cycle times for all aircraft models are shown in Figure 4c. A key feature for predicting the theoretical number of vehicles is average cycle length, which in this case study corresponds to $31.51 \mathrm{~min}$ for the AS350 model; 46.62 min for Bell Huey H1 model; 40.62 min for the UH-60 model; 54.12 min for the AS332 model; and 54.47 min for the EC725 model. 


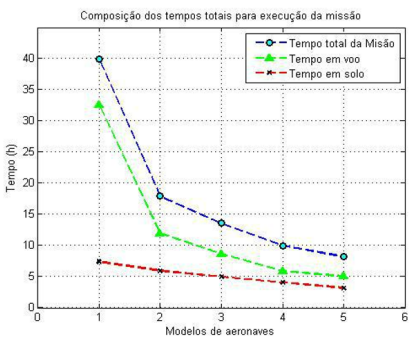

(a)

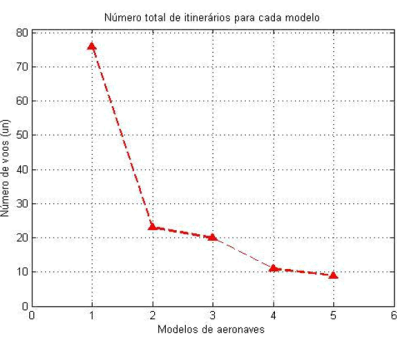

(b)

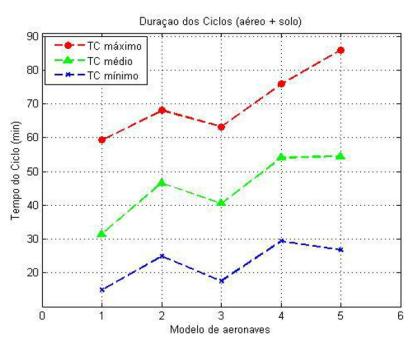

(c)

Figure 4. Composition of mission execution times $x$ vehicle models (a), Number of Itineraries $x$ vehicle models $(b)$, and number of itineraries $x$ vehicle models $(c)$.

When evaluating the maximum, minimum and average occupancy rates of each type of vehicle, it is possible to identify that all vehicle models, at least in the moments of direct attendance time, use all its passenger capacity (load 100\%). Average occupancy rates are higher than $88 \%$, demonstrating that the optimization applied has made it possible to obtain optimum use of the passenger capacity of vehicles.

When estimating the theoretical minimum number of aircraft by Equation 10, it was found that four AS350 aircraft, or two Bell Huey H1 or UH-60 aircraft are required, or only one aircraft if AS332 or EC725 models are used. In order to illustrate the optimal itinerary solution for two aircraft, AS350 and EC 725, the routes with 3 points of direct service and the routes that have more than 3 points are presented in Figure 5 .

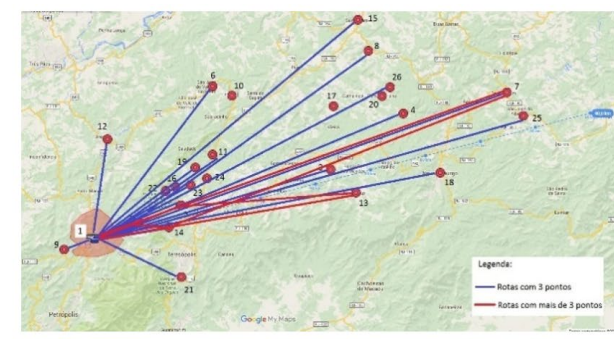

(a)

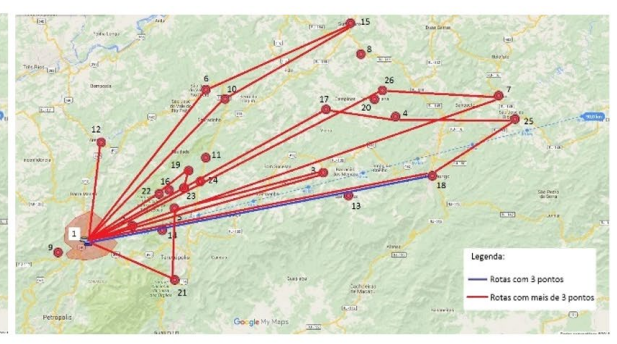

(b)

Figure 5. Routes obtained using aircraft AS 350 (a) and routes obtained using aircraft EC 725 (b).

\subsection{SENSITIVITY ANALYSIS}

This section presents an analysis of the results obtained for the scenario of situation 1 , evaluating the sensitivity of the number of itineraries and number of vehicles by changing the parameters operating speed, duration of the maximum workday (windows of opportunity), loading time and increased load capacity by decreasing autonomy.

Weather conditions or air traffic rules established in the affected region may require aircraft to perform their missions at different speeds. In this way, the operating speed changes for each of the five helicopter models are changed to speeds of $90 \mathrm{~km} / \mathrm{h}$, $120 \mathrm{~km} / \mathrm{h}, 150 \mathrm{~km} / \mathrm{h}, 180 \mathrm{~km} / \mathrm{h}, 210 \mathrm{~km} / \mathrm{h}$ and $240 \mathrm{~km} / \mathrm{h}$. H. Figures $6 a$, b and c show the results obtained after changing cruising speed. 


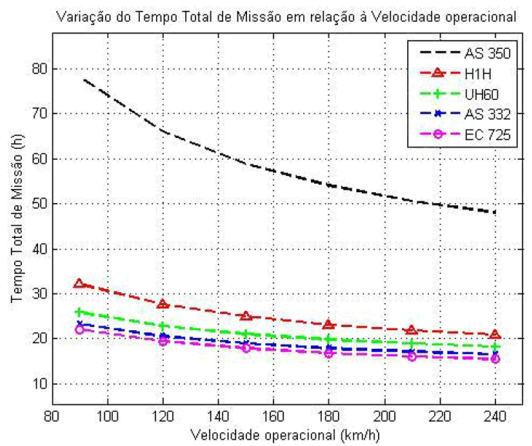

(a)

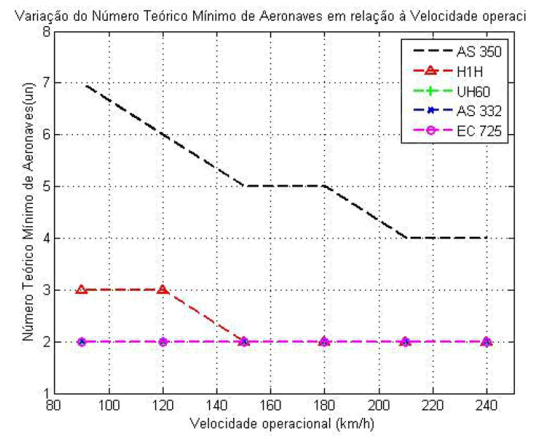

(b)

Figure 6. Influence of the operating speed on total task time (a) and in fl uence of the operating speed on theoretical minimum number of aircraft (b).

Figure 6a shows that reducing operational speed implies a longer total mission duration. Since the change in velocity implies an increase of the average cycle times, it is verified in Figure $6 \mathrm{~b}$ that some aircraft designs have variations in the theoretical minimum number of aircraft. The change of the operating speed of the aircraft AS350, for example, has great influence on the definition of the number of vehicles: for a speed of $90 \mathrm{~km} / \mathrm{h} 7$ aircraft are required; for $180 \mathrm{~km} / \mathrm{h}, 5$ aircraft are required; and for the cruising speed of $235 \mathrm{~km} / \mathrm{h}$ only 4 aircraft would be sufficient for the mission. The minimum number of AS 332 and EC 725 aircraft did not change with varying operating speeds.

A second analysis was performed in order to verify the influence of the maximum working hours of operation, ie, the windows of opportunity. Through Figure $7 \mathrm{a}$, it is observed that the variation of the maximum working hours set for routes and for vehicles does not change due to the total mission time, because the variation of the working day does not have any influence on number and characteristics of the itineraries, that is, their missions remained the same. There was also no change in estimates of total mission time and logistics cost. However, for the Logistic Air Transport operation to be successfully completed, it is necessary to mobilize large numbers of vehicles as we narrow the window of opportunity (Figure $7 \mathrm{~b}$ ).

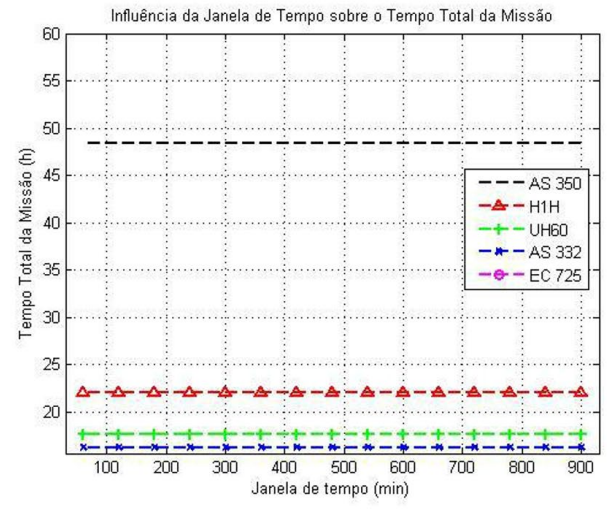

(a)

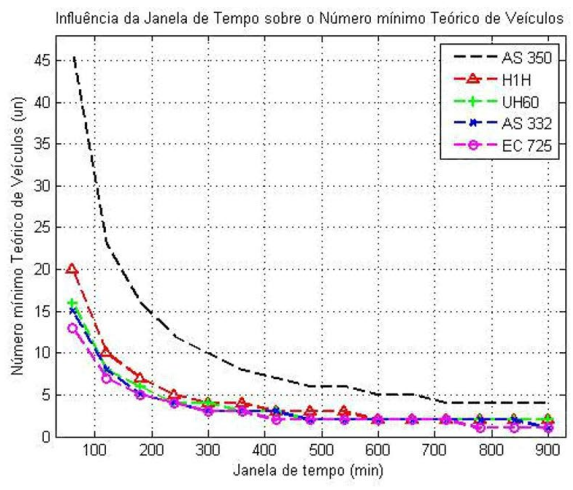

(b)

Figure 7. Influence of the window of opportunity on the total mission time (a) influence of the window of opportunity on theoretical minimum number of aircraft (b). 
In summary, the influences of the windows of opportunity are observed as one of the limitations of the model proposed in step 5 , because although the number of aircraft increased considerably, the cost of the operation remained constant. This fact is justified since the model has its focus on minimizing the time of the mission, thus being defined that the cost of the operation would depend solely on the amount of flight hours, leaving aside the cost fixed for each allocated aircraft.

Finally, following the analysis strategy Clementson \& Fisher (2011) that suggests managing the payload available through realization of the trade-off between load and fuel in air transport operations by helicopters, the sensitivity of the mission performance could be noticed by withdrawing fuel to increase the burden of humanitarian aid. In this analysis, only the medium-sized aircraft were considered, cargo changes were made on the itineraries in the order of $100 \mathrm{~kg}$, reducing the cargo carrying capacity by $400 \mathrm{~kg}$, ie, prioritization of fuel or other auxiliary equipment, ranging up to $+400 \mathrm{~kg}$ in capacity increase, in this case prioritization of the supply load over fuel, crew or equipment.

Figure 8 a highlights the increase in load capacity over a ratio inversely proportional to load variation, with the Bell Huey $\mathrm{H} 1$ model having the highest rate of change related to load capacity. The increase in load capacity also has an influence on the number of itineraries that are carried out at full load, as shown in Figure 8b. As model capacity is increased, the model can perform more itineraries. In turn, as the number of points served on an itinerary increases, the average cycle time also increases. On the other hand, as shown in Figure 8c, increased vehicle capacity and increased average cycle time require fewer aircraft for some models.
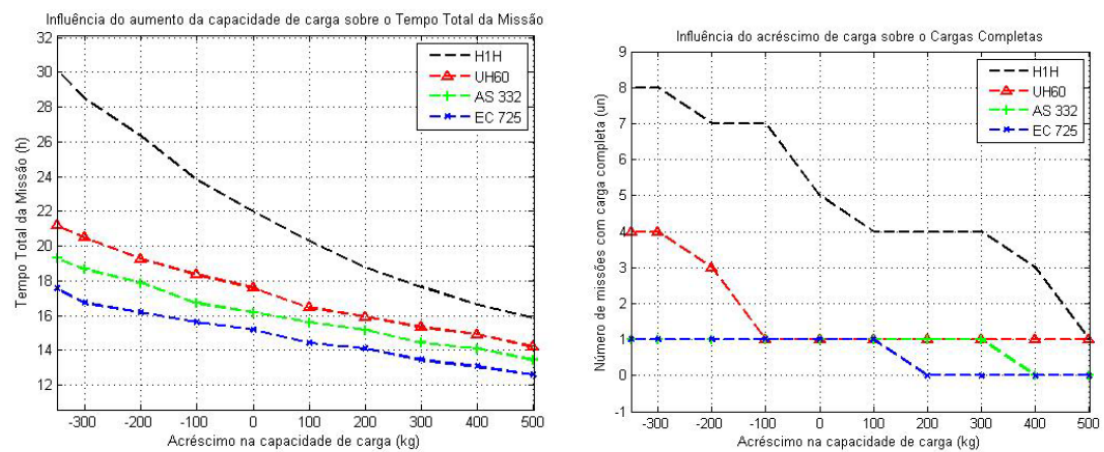

(a)

(b)

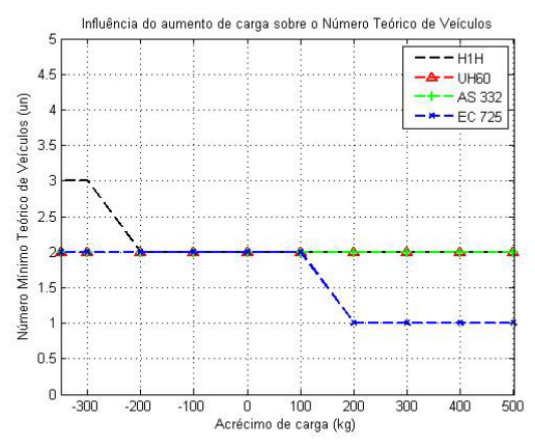

(c)

Figure 8. Influence of increased load capacity on total mission time (a), number of full-load trips (b) and minimum theoretical number of aircraft 


\section{CONCLUSIONS}

The present article aimed to present a proposal of procedure to assist in decisionmaking during the planning of helicopter employment for logistic air transport activities in response to sudden disasters.

The proposed procedure consists of five steps. Steps from 1 to 4 are required to define the parameters and constraints that are implemented in Step 5, which deals with measuring the air effort to distribute the last mile of the humanitarian supply chain. The procedure makes it possible to evaluate if the available aircraft are sufficient, and to define the itineraries that minimize the amount of flight hours. It is noteworthy that, during the disaster response operation, the procedure should be reviewed periodically, by updating the main parameters so that the allocated air resources can be adjusted and mission itineraries can be defined. Once the impacted infrastructure is recovered, helicopter employment is expected to be reduced and consequently so are the costs, until aerial means are completely demobilized (Comaer, 2013).

The application of the proposed procedure to the case study allowed a demonstration of the importance and challenges of decision-making on the deployment of air transport logistics, using helicopters for distribution of supplies and personnel in the last mile of humanitarian chain. The importance of data and information on the affected area was verified for the quality of the decision on the definitions of the last mile distribution. The application of the procedure also allowed us to quickly verify if the amount of aircraft available in the mobilization plan is sufficient to meet the demands. If the available aircraft are not sufficient, the decision-maker will have subsidies to decide upon the urgency and need to request the mobilization of new resources.

One of the restrictions observed on helicopter use throughout this article is associated with the weather conditions of the affected region. Such situations may require the execution of flights to check with lower speed or taking advantage of the available time slots. In these circumstances, it is advisable to use proper packaging, staff training, template building and staffing for loading and unloading stages, especially in the improvised regions, where solidarity currents are often formed for unloading the aircraft.

The results obtained in the sensitivity analysis showed that there are many possibilities to structure a transport system that meets the limitations and conditions of use of the aircraft after the disaster. Through this procedure, the decision-maker will be able to evaluate various situations of employment hypothesis, anticipating the possible results, difficulties and viable alternatives. Thus, in the Brazilian scenario, the proposed model can be used by both the Brazilian Air Force and SINPEDEC to assist in tactical and operational planning in response to critical situation events.

As a final analysis of the study, it can be argued that the mathematical modeling process for post-disaster helicopter air transport planning contributes significantly to highlighting the importance and need for logistics air transport planning and

preparation. For prompt service, the humanitarian and civil defense organizations that comprise SINPEDEC must be prepared and willing to work together.

Finally, as a suggestion for future work, it is recommended to carry out an integrated planning of helicopters, considering, in addition to logistic air transport, the other response activities foreseen for a sudden disaster, such as search and rescue and aeromedical evacuation and to approach other cases, with multiple aircraft and use dynamic programming. 


\section{Acknowledgment}

This study was financed in part by the Coordenação de Aperfeiçoamento de Pessoal de Nível Superior - Brasil (CAPES) - Finance Code 001.

\section{References}

Abreu, W. F. (2008). O emprego de aeronaves de asa fixa orgânicas na Aviação do Exército (Doutorado). Escola de Comando e Estado-Maior do Exército, Rio de Janeiro. 144 p.

Balcik, B., Beamon, B., \& Smilowitz, K. (2008). Last mile distribution in humanitarian relief. Journal of Intelligent Transport Systems, 12(2), 51-63. http://dx.doi.org/10.1080/15472450802023329.

Battini, D., Peretti, U., Persona, A., \& Sgarbossa, F. (2014). Application of humanitarian last mile distribution model. Journal of Humanitarian Logistics and Supply Chain Management, 4, 131-148. http://dx.doi.org/10.1108/JHLSCM-01-2013-0001.

Benini, A., Conley, C., Dittemore, B., \& Waksman, Z. (2009). Survivor needs or logistical convenience? Factors shaping decisions to deliver relief to earthquake. Pakistan 2005-06. Disasters, 33, 110-131.

Brasil. Ministério da Defesa. (2013, 8 de março). Portaria Normativa No 620/MD, de 8 de março de 2013. Dispõe sobre o "Manual de Transportes para uso nas Forças Armadas". Brasília, DF: Diário Oficial da República Federativa do Brasil.

Brasil. Ministério da Defesa. (2014a). Manual de Campanha EB70-MC-10.214: Vetores Aéreos da Força Terrestre. Brasília: MD.

Brasil. Ministério da Defesa. (2014b). Plano de contingência de proteção e defesa civil. Rio de Janeiro: Prefeitura de Petrópolis.

Clementson, T., \& Fisher, C. (2011). Analysis of u.s. military helicopter operations in support of humanitarian assistance and disaster relief. Monterey, CL: MBA Professional, Naval PostGraduate School.

Clarke, G., \& Wright, J. (1964). Scheduling of Vehicles from a central depot to a number of delivery points. Operations Research, 12(4), 568-581. http://dx.doi.org/10.1287/opre.12.4.568.

Comando da Aeronáutica - COMAER. (2005). Manual de Condução de Operações Aéreas (Vol. MCA 55-10). Rio de Janeiro: COMAER.

Comando da Aeronáutica - COMAER. (2011). Relatório Final de Operação fan 122 - relifn 01/2001 (pp. 1-33). Rio de Janeiro: COMAER.

Comando da Aeronáutica - COMAER. (2013). IOC PRO-15: Emprego da II FAE em caso de desastres. Rio de Janeiro: COMAER.

Costa, S. R. A., Bandeira, R. A. M., Campos, V. B. G., \& Mello, L. C. B. B. (2015). Cadeia de suprimentos humanitária: uma análise dos processos de atuação em desastres naturais. Production, 25(4), 876-893. http://dx.doi.org/10.1590/0103-6513.147513.

Gama, M. B. (2011). Roteirização de Veículos: Implementação e melhoria do método de Clarke e Wright (Trabalho de conclusão de curso). Universidade do Vale do São Francisco, Juazeiro, Bahia. 93 p.

International Federation of Red Cross and Red Crescent Societies - ICRC. (2008). Guidelines for assessment in emergencies. Geneva: ICRC.

Kapucu, N. (2011). The role of the military in disaster response in the US. European Journal of Economic \& Political, 4, 7-33.Kovács, G., \& Spens, K. (2007). Humanitarian logistics in disaster relief operations. International Journal of Physical Distribution \& Logistics Management, 37(2), 99-114. http://dx.doi.org/10.1108/09600030710734820. 
Lopes, L. A. S. (1987). Planejamento de transporte militar por aviões (Mestrado). Instituto Militar de Engenharia, Rio de Janeiro.

Myers, S. L. (1998). Integrating helicopter and triltor assets into disaster relief planning. (FAA, vol. AC 00-59, pp. 1-82. Federal Aviation Administration: U.S. Department of Transportation.

Mazzotti, M. A. (1987). Planejamento de transporte militar por helicópteros (Mestrado). Instituto Militar de Engenharia, Rio de Janeiro.

Oloruntoba, R., \& Gray, R. (2006). Humanitarian aid: an agile supply chain? Supply Chain Management, 11(2), 115-120. http://dx.doi.org/10.1108/13598540610652492.

Ozdamar, L. (2011). Planning helicopter logistics in disaster relief. OR-Spektrum, 33(3), 655672. http://dx.doi.org/10.1007/s00291-011-0259-y.

Pan-American Health Organisation - PAHO. (2008). Manual Logistical Management of Humanitarian Supply. Washington, DC: PAHO.The International Disaster Database - EMDAT. (2015). Retrieved in 2015, may 1, from http://www.emdat.be/database

U.S. Air Force - USAF. Secretary of The Air Force. (2011). Air Mobility Planning Factors. Number Operations. Washington, DC: USAF.

U.S. Army. (2014). ATP 4-48 - Aerial Delivery (pp. 4-48). Virgínia, U.S.

Xavier, I. R. (2016). Procedimento para planejamento do emprego de helicópteros no transporte aéreo logístico em desastres naturais (Mestrado). Instituto Militar de Engenharia, Rio de Janeiro.

Xavier, I. R., Bandeira, R. A. D. M., \& Bandeira, A. D. P. F. (2015). Revisão do emprego de helicópteros em desastres naturais. In Anais do XXIX Congresso Nacional de Ensino e Pesquisa em Transporte da Anpet. Volume Logística (pp. 450-461). 